\title{
Researches on ecological weed control in vegetable crops
}

\author{
Adriana Muscalu ${ }^{1, *}$, Cristian Sorică ${ }^{1}$, Cătălin Persu ${ }^{1}$, Ana-Maria Andrei ${ }^{2}$, Angela \\ Dorogan $^{3}$ and Cătălina Tudora ${ }^{1}$ \\ ${ }^{1}$ INMA, 6 Ion Ionescu de la Brad Blvd., Bucharest, 013811, Romania \\ ${ }^{2}$ ICDPP, 8 Ion Ionescu de la Brad Blvd., Bucharest, 013813, Romania \\ ${ }^{3}$ INCDTP, 16 Lucretiu Pătrășcanu., Bucharest, 030508, Romania
}

\begin{abstract}
In recent years, intense concerns about the increasing resistance of weed populations to herbicide treatments, the low availability of bioactive ingredients for vegetable crops, as well as the expansion of organic farms for these niche crops have stimulated the development of new non-chemical methods of control or new approaches to those already used. In general, vegetable crops exhibit increased sensitivity to weeds compared to other crops. Therefore, weed control in organic vegetable crops is a real challenge for farmers, mainly using the so-called physical combat methods. Therefore, weed destruction is accomplished by using manual, mechanical, thermal or mulching means. The paper presents the preliminary experimental results obtained under laboratory conditions, referring to an innovative model of equipment for the ecological weed control in vegetable crops. It will achieve the destruction of weeds, combining the thermal method based on using hot water with the mechanical one, by equipping the machine with environmentally friendly active parts. The results obtained constitute an important premise for developing efficient equipment for the ecological weed control that can be used within integrated control systems, specific for organic onion, bean and bell pepper crops.
\end{abstract}

\section{Introduction}

The quality of agricultural products is a topic that has raised the interest of the general public, especially in recent years, when specialty studies have demonstrated the importance and beneficial effects of healthy eating. This involves a certain way of life as well as the consumption of healthy foods, especially "bio products". According to market studies conducted in EU countries, the consumption level of these products ranges between $3 \%$ and $13 \%$ for permanent consumers and between $23 \%$ and $53 \%$ for occasional consumers [1].

This context as well as the indications of nutritionists recommending higher consumption of vegetables has led to the development of organic farming for these species, for which the food and therapeutic value increases in these circumstances. [2]. Organic cultivation of vegetables ranks between so-called "minor" or niche crops, which provide

\footnotetext{
${ }^{*}$ Corresponding author: amuscalis@yahoo.com
} 
productions representing more than $20 \%$ of the total value of agricultural production in the European Union [3].

In general, vegetable crops have increased sensitivity to weeds compared to other crops [4]. Weed control in vegetable crops without synthetic herbicides, according to the rules of organic farming, is one of the greatest challenges faced by vegetable growers [5].

The development of new non-chemical control methods or new approaches to those already used has been stimulated by weed populations' increase in resistance to herbicides and by the low availability of specific bioactive ingredients used for these crops [6]. Nonchemical weed control of organic vegetable crops is performed with mechanical and thermal methods, using characteristic equipment, which represent the traditional physical means $[7,8]$.

Cultivation of vegetables in organic farming attaches great importance to soil works, crop rotation, as well as to soil fertilization. Some of these are even preventive weed control measures. To these are added the crop maintenance works (curative control measures) made with specialized equipment, intensely developed in the last period. Their action was intensified by the use of new active parts (brush, fingers, basket type, etc.) or intelligent equipment capable of recognizing and controlling weeds in vegetable crops $[3,6]$.

The method of thermal control is based on heat transfer between an installation and harmful plants through foliar contact. For each type of crop, different techniques of thermal weed control should be created / adapted, ensuring the protection of cultivated plants [9]. Most of the researches in this regard have used treatments with: infrared radiation, flame, hot air, steam, hot water, saturated steam, etc. Short-term, sudden heating causes cellular protein distortion and protoplasm expansion, which leads to the elimination of water from weed tissue, causing damage to/destruction of the vital functions of the plant parts above the ground [9-11]. Applying the methods based on moist heat (steam, hot water, saturated steam with boiling water, etc.) is more convenient, being a little more efficient and less harmful to the environment. Hot water treatments can improve the bio-herbicidal potential of some pathogens (fungi). [5,9,10,12].

The paper presents an experimental model of weed control equipment for organic onion, bean and bell pepper crops, combining the thermal and mechanical methods. By using an electrical energy source, supplemented by the recovered energy, the environment will be protected. Finding a clean method of controlling weeds in vegetable crops and implicitly of lowering the prices of maintenance works for organic onion, bean and bell pepper crops is aimed at.

\section{Material and method}

The experimental model of organic weed control equipment for vegetable crops uses hot water as control agent, the action of which is completed by that of environmentally friendly active parts, of finger weeder type.

\subsection{Organic weed control equipment}

\subsubsection{Description and operating principle}

Considering that hot water flows gravitationally compared to steam and hot air, with a very good thermal conductivity, it can provide a higher heat transfer (approximately 23-27 times higher) compared to the other heat agents presented in Table 1, but in a slightly longer time $[10,13]$. 
Table 1. Physical properties

\begin{tabular}{|c|c|c|}
\hline $\begin{array}{c}\text { Control agent } \\
\left(\mathrm{T}=100^{\circ} \mathrm{C}, \mathrm{p}=1 \text { bar }\right)\end{array}$ & $\begin{array}{c}\text { Specific heat } \\
\mathrm{kJ} /(\mathrm{kg} \mathrm{K})\end{array}$ & $\begin{array}{c}\text { Thermal } \\
\text { conductivity } \\
\mathrm{W} /(\mathrm{m} \mathrm{K})\end{array}$ \\
\hline Hot air & 1.01 & 0.03 \\
\hline Hot water & 4.18 & 0.682 \\
\hline Steam & 2.08 & 0.025 \\
\hline
\end{tabular}

Controlling weeds with non-chemical methods depends on some technical-economic peculiarities of vegetable crops [3]. Organic control equipment (Figure 1) is intended for use on both shaped and flat land. The mobile frame (b) as well as the fastening systems of the nozzle holders (5), respectively of the active parts (d), allow their correct positioning reported to the soil and plants, according to the planting schemes for each culture. Nozzle holders also allow adjusting the distance between the insulated sidewalls, which are designed to adapt the thermal agent action zone to the spacing between plant rows. Hot water distribution nozzles are grouped by two, one after the other, to accentuate the control effect of hot water on weeds.

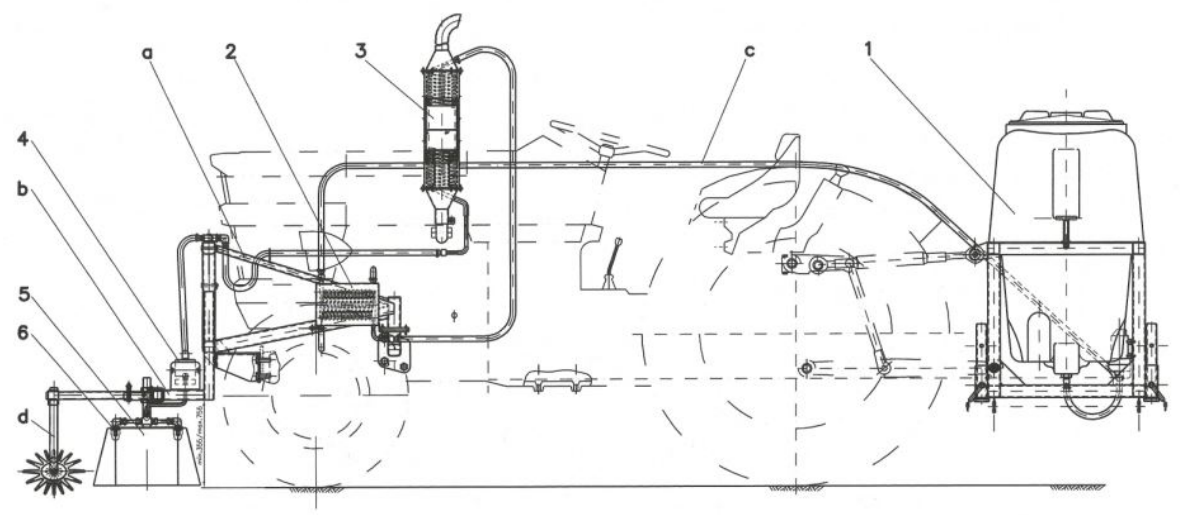

Fig.1 Experimental model of organic control equipment

$\mathrm{a}$ - fixed frame; $\mathrm{b}$ - mobile frame; $\mathrm{c}$ - heating and distribution installation ( 1 - tank, 2 - preheating system; 3 - heat recovery system; 4 - boiler type electrical resistance; 5 - nozzle holders; 6 - nozzles); $\mathrm{d}$ - finger weeder

To be used as a control agent, the water in the tank needs to be heated. The process takes place step by step, being initiated in the pre-heating system, where the control agent takes over the heat of the water from the tractor radiator, which washes the spiral from the copper pipe through which it flows. The heating process continues in the heat recovery system, which is an exhaust pipe with heat recovery of exhaust gas, resulting from the tractor engine. It replaces the classic exhaust pipe of the tractor, consisting of a cylindrical body, to which the upper and lower caps are attached with screws, in the area of which there is a copper pipe spiral, through which the preheated water circulates. Flue gas, with a very high temperature at the engine exit, "washes" the spiral. [14,15]. Control agent heating is completed by means of a boiler type electrical resistance. Then, the hot water is distributed over the weeds, using the nozzles [16]. The equipment is fitted according to the scheme in figure 2, with two electrical resistances, the operation of which is controlled by electrical valves. 


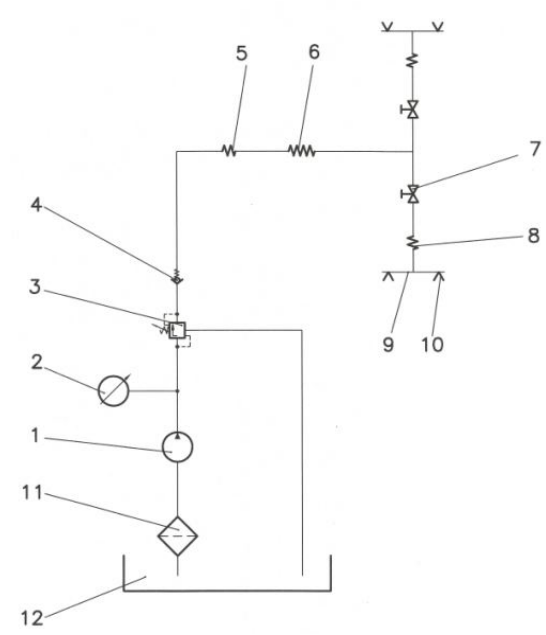

Fig. 2 Conventional scheme of hot water heating and distribution installation 1. Electric pump, 2. Manometer, 3. Pressure regulator, 4. Check valve, 5. Pre-heating system, 6. Heat recovery system, 7. Electrical valve, 8 . Boiler type electrical resistance, 9. Nozzle holders, 10. Nozzle.

\subsubsection{Technical characteristics}

The main technical and functional characteristics of the experimental model of organic weed control equipment for vegetable crops are: pump supply voltage: $12 \mathrm{~V} \mathrm{dc}$; fluid pressure in the installation: max. 2 bar; water tank capacity: 3001 ; number of operation intervals: 1-2 spaces between the plant rows; number of nozzle holders: 2 pcs .; number of nozzles: 4 pcs .; working width: 215-600 mm; mobile frame adjustment height: $400 \mathrm{~mm}$; no. active parts: $2 / 4$; active parts working depth: $2-4 \mathrm{~cm}$.

\subsection{Testing method}

Laboratory experiments aimed at monitoring and determining some characteristics of the thermal agent, which are important to the control process. These refer to hot water temperature at the outlet of the nozzle, respectively the flow rate and the working pressure. Also, the uniformity of thermal agent volume distribution through the nozzles was followed, determining a coefficient of variation.

First, were connected to the tractor power source the pump and the boiler type electrical resistance, the latter requiring a pre-heating period of 60 seconds to reach the maximum temperature. After contact with the resistance, the temperature of the water from the tank was determined, at the outlet of the nozzle. Thus, it has been found that the temperature variation of the thermal agent is $\Delta \mathrm{T}=20-23^{\circ} \mathrm{C}$, under the conditions of its initial temperature of $\mathrm{T}_{\mathrm{i}}=11^{\circ} \mathrm{C}$.

Previously, we showed that the thermal agent heating process takes place step by step, depending on the operation of the tractor thermal engine afferent to the equipment. For this reason, it was necessary a period of 10-15 minutes of operation in advance, in order to reach the operating temperature. After the necessary preparation periods, the experimental determinations were carried out, under the operating conditions of the heating and distribution installation, in order to obtain the temperatures of the thermal agent, the pressure and the working flow. For this purpose, specific equipment such as: "Ama-digit $20^{\text {th }}$ digital thermometer, mechanical timer, graduated cylinder, etc. was used. 
To determine the coefficient of variation for volume distribution of the liquid sprayed through nozzles, the following equation was used:

$$
C V_{\text {flow }}=100 \cdot \frac{\sigma_{\text {flow }}}{V_{m}},
$$

where $\sigma_{\text {flow }}$ - standard deviation of the volumes collected from nozzles in one minute;

$V_{m}$ - average volume collected from nozzles in one minute.

The standard deviation of the volumes collected from nozzles was determined using the following equation:

$$
\sigma_{\text {flow }}=\sqrt{\frac{\sum\left(V_{i}-V_{m}\right)^{2}}{n-1}},
$$

where $V_{i}$ - volume of liquid collected from the nozzle ,i” in one minute;

$n$ - number of nozzles.

The coefficient of variation for volume distribution of the liquid sprayed through nozzles, is a quality indicator for the spraying process and represents the ratio between the standard deviation and the average, expressed in percent. It points out the homogeneity of the values obtained and also the level of dispersion towards the average. Practically, this indicator shows if the spraying nozzles are properly calibrated by the producer and homogeneously distribute the liquid.

\section{Results and discussions}

Table 2 shows the mean values of control agent main characteristics, which influence the process, determined under laboratory conditions.

Table 2. Control agent characteristics (hot water).

\begin{tabular}{|c|c|c|c|}
\hline Determination & $\begin{array}{c}\text { Working } \\
\text { pressure } \\
\text { (bar) }\end{array}$ & $\begin{array}{c}\text { Nozzle } \\
\text { flow } \\
(1 / \text { min })\end{array}$ & $\begin{array}{c}\text { Output } \\
\text { temperature } \\
\left({ }^{0} \mathrm{C}\right)\end{array}$ \\
\hline 1 & 2 & 0.91 & 68.3 \\
\hline 2 & 1.8 & 0.87 & 77.6 \\
\hline 3 & 1.6 & 0.82 & 80.4 \\
\hline 4 & 1.4 & 0.78 & 84.9 \\
\hline
\end{tabular}

The minimum temperature of the thermal agent should be as high as possible since, in order to direct heat to the plant, the highest possible temperature gradient is necessary. For effective control, the temperature of the control agent at the outlet of the nozzle must be as close to the boiling point of water as possible, so it must reach values of at least $95^{\circ} \mathrm{C}$. The recorded temperatures are below these values, generated both by the low temperature of water in the tank, at the time of the experiments, and by the heat losses recorded along the route.

Table 3 shows the average values of hot water volumes, distributed through each nozzle in one minute, obtained from three repetitions for each of them, corresponding to each considered working pressure. 
Table 3. Qualitative indices related to the volume of liquid sprayed by nozzle in one minute

\begin{tabular}{|c|c|c|c|c|c|}
\hline \multirow{2}{*}{$\begin{array}{l}\text { Qualitative } \\
\text { indices }\end{array}$} & \multirow{2}{*}{$\begin{array}{l}\text { Working } \\
\text { pressure } \\
\text { (bar) }\end{array}$} & \multicolumn{4}{|c|}{ Nozzle no. } \\
\hline & & 1 & 2 & 3 & 4 \\
\hline \multirow{4}{*}{$\begin{array}{c}\text { Average } \\
\text { volume per } \\
\text { nozzle } V_{i} \\
\text { (l) }\end{array}$} & 2.0 & 0.91 & 0.92 & 0.88 & 0.90 \\
\hline & 1.8 & 0.87 & 0.88 & 0.85 & 0.86 \\
\hline & 1.6 & 0.82 & 0.82 & 0.80 & 0.81 \\
\hline & 1.4 & 0.78 & 0.79 & 0.77 & 0.78 \\
\hline \multirow{4}{*}{$\begin{array}{c}\text { Average } \\
\text { volume } V_{\boldsymbol{m}} \\
\text { (1) }\end{array}$} & 2.0 & \multicolumn{4}{|c|}{0.90} \\
\hline & 1.8 & \multicolumn{4}{|c|}{0.86} \\
\hline & 1.6 & \multicolumn{4}{|c|}{0.81} \\
\hline & 1.4 & \multicolumn{4}{|c|}{0.78} \\
\hline \multirow{4}{*}{$\begin{array}{l}\text { Coefficient of } \\
\text { variation for } \\
\text { the volume } \\
\text { distribution } \\
C V_{\text {flow }} \\
(\%)\end{array}$} & 2.0 & \multicolumn{4}{|c|}{1.44} \\
\hline & 1.8 & \multicolumn{4}{|c|}{1.34} \\
\hline & 1.6 & \multicolumn{4}{|c|}{1.23} \\
\hline & 1.4 & \multicolumn{4}{|c|}{1.04} \\
\hline
\end{tabular}

Figure 3 shows the average volume of control agent sprayed in one minute and the coefficient of variation for its volume distribution, depending on the working pressure.

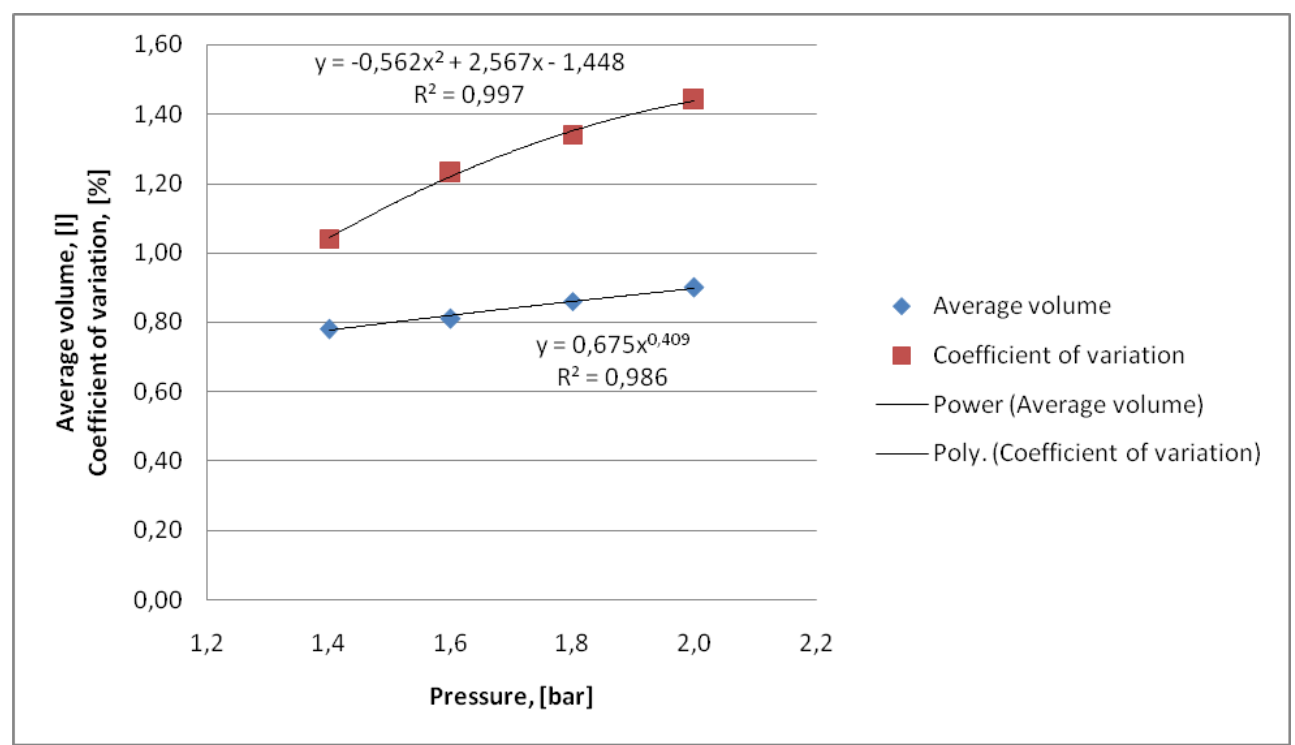

Fig. 3. Dependence of the average volume of control agent sprayed in one minute and of the coefficient of variation of its volume distribution on the working pressure 
Linear regression, performed using Excel, allowed the identification of a power function which estimates the variation of the average volume of liquid sprayed through nozzles within one minute depending on the working pressure, with a coefficient of determination equal to 0.986 . Also, a second-degree polynomial function has been identified, which estimates the coefficient of variation depending on the working pressure, with a coefficient of determination equal to 0.997 .

\section{Conclusions}

The coefficient of variation for volume distribution of the liquid sprayed through nozzles has a maximum value of $1.44 \%$ which is less than the statistical conventional limit of $5 \%$, below this limit the distribution being considered very homogeneous and the average value of volume is representative. These results show that the spraying nozzles are properly calibrated by the producer and homogeneously distribute the liquid through nozzles.

To improve the efficiency of the water heating and distribution installation, boiler type electrical resistances with greater power will be used. Experimental research on weed control will be continued under real operating conditions to assess the process effect on weeds in organic vegetable crops.

The equipment combines two methods of non-chemical weed control, not using any other source of environmentally harmful extra energy, except for the particulate matter generated by fuel combustion required for the self-driving of the tractor on which the equipment is mounted.

The results obtained are an important starting point for the production of efficient weed control equipment, which contributes to the development of organic onion, bean and bell pepper crops and of integrated protection systems, specific to these crops.

\section{Acknowledgement}

The work was supported by a grant of the Romanian Ministry of Research and Innovation, CCCDI - UEFISCDI project number PN-III-P1-1.2-PCCDI-2017-0659 / Nr.11 PCCDI/2018, within PNCDI III and a grant of the Romanian Research and Innovation Ministry, through Programme 1 - Development of the national research-development system, sub-programme 1.2 - Institutional performance - Projects for financing excellence in RDI, contract no. 16PFE.

\section{References}

1. D. Matei, I.S. Brumă, L. Tanasă, International Journal of Communication Research, 6(1), ISSN 2246-9265, Iași, 7, (2016);

2. P. Skerret, W. Willett, J Midwifery, Women's Health, 55 (6), 10 (2010)

3. E. Pannaci, B. Lattanzi, F. Tei, J. Crop Protection, 96, 14 (2017)

4. M. Fontanelli, M. Raffaelli, L. Martelloni, C. Frasconi, M. Ginanni, A. Peruzzi, Spanish Journal of Agricultural Research 11 (3), 10 (2013),

5. A.S. El-Sayed, G. M. El-Hameed, The Role of Agricultural and Biological Engineering for Advancement of the Agricultural Sector, Proceedings of $5^{\text {th }}$ International Conference for Agricultural \& Bio-engineering, 25-27 September, Cairo, Egypt, 30 (2017) 
6. A. Peruzzi A., L. Martelloni L., C Frasconi, M. Fontanelli, M. Pirchio, M. Raffaelli M. Journal of Agricultural Engineering, XLVIII, 583 (14), (2017)

7. D.L. Shaner, H.J. Beckie H.J. Pest Management Science 70 (9), 11 (2014)

8. O.Z. Bundza, O.O. Nalobina, V.G. Nikitin, O.L. Tkachuk, INMATEH - Agricultural Engineering, 52(2), 6 (2017)

9. J. Nadzeikienè, A.P. Sirvydas, R. Čingienè, R. Vasinauskienè, P. Kerpauskas, J. Agronomy Research, 7(I), 5 (2009)

10. P. Kristoffersen, A. M. Rask, S. U. Larsen, Weed Research, 48(1), 7 (2008)

11. J. Ascard, P.E. Hatcher, B. Melander, M.K. Upadhyaya, Thermal weed control. In: Upadhyaya, M.K., Re Blackshaw, R.E. (Eds.), Non-chemical Weed Management Principles, Concepts and Technology. CABI Press, Oxfordshire, UK, 21 (2007)

12. C.D. Boyette, R.E. Hoagland, K.C. Stetina, American J., Plant Sciences, 9, 10 (2018)

13. F.T. Tanasescu, V. Stanciu, S. Nitu, Technical Agenda, Technical Publishing House, Bucharest, (1990)

14. Gh. Socaciu, M. Matache, M. Marian, A. Muscalu, M. Bîrsan Patent application No. A - 00504/21.07.2017 Exhaust pipe with heat recovery of exhaust gas (2017)

15. A. Tiwari, H. Vadnani, N. Kumari, M. Labana, IJRSAE, 6(9), 16 (2017)

16. A. Muscalu, C. Perșu, I. Ganea Hristu, G. Bolintineanu, C. Tudora, Patent application No. A - 0002/16.01.2019 Equipment for weed destruction in vegetable growing (2019). 